\title{
BMJ Associations between deprivation and Open rates of childhood overweight and obesity in England, 2007-2010: an ecological study
}

\author{
David Conrad, ${ }^{1}$ Simon Capewell ${ }^{2}$
}

To cite: Conrad D, Capewell $\mathrm{S}$. Associations between deprivation and rates of childhood overweight and obesity in England, 2007-2010: an ecological study. BMJ Open 2012;2: e000463. doi:10.1136/ bmjopen-2011-000463

- Prepublication history for this paper is available online. To view this file please visit the journal online (http://dx. doi.org/10.1136/

bmjopen-2011-000463).

Received 7 October 2011 Accepted 12 March 2012

This final article is available for use under the terms of the Creative Commons Attribution Non-Commercial 2.0 Licence; see http://bmjopen.bmj.com

${ }^{1}$ Centre for Men's Health, Leeds Metropolitan University, Leeds, UK ${ }^{2}$ Department of Public Health and Policy, University of Liverpool, Liverpool, UK

Correspondence to David Conrad; d.conrad@nhs.net

\section{ABSTRACT}

Objectives: To investigate the associations between deprivation and rates of childhood overweight and obesity in England, from 2007 to 2010.

Design: An ecological study using routine data from the National Child Measurement Programme and Indices of Multiple Deprivation (IMD) 2010 scores.

Setting: Local authority districts in England. Participants: Schoolchildren in Reception year (age 4-5 years) and Year 6 (age 10-11 years) attending non-specialist maintained state schools in England.

\section{Primary and secondary outcome}

measures: Prevalence of overweight in both Reception and Year 6, prevalence of obesity in both Reception and Year 6 and IMD 2010 scores for each local authority.

Results: In 2009-2010, local authority IMD 2010 scores were strongly correlated with obesity rates among schoolchildren in Reception $(r=0.625$, $p<0.001)$ and Year $6(r=0.733, p<0.001)$. There were no statistically significant changes in association between obesity in Reception or Year 6 and IMD from 2007-2008 to 2009-2010. In contrast, the prevalence of overweight was not statistically significantly correlated with local authority IMD scores in Reception ( $r=0.095, p=0.092)$ and only weakly correlated in Year $6(r=0.184, p=0.001)$. There were no statistically significant changes in association between overweight in Reception or Year 6 and IMD from 2007-2008 to 2009-2010.

Conclusions: Childhood obesity rates in England are strongly associated with deprivation. Given the enormous public health implications of overweight and obesity in the population, these findings suggest that significant effort is required to tackle unhealthy weight in children in all local authorities and that this should be a priority in areas with high levels of deprivation.

\section{INTRODUCTION}

In response to growing fears of an obesity pandemic, ${ }^{1}$ the National Child Measurement Programme (NCMP) was established in 2005 to annually record the weights and heights of schoolchildren in Reception year (age

\section{ARTICLE SUMMARY}

\section{Article focus}

- Associations between local authority 2010 IMD scores and prevalence of overweight and obesity in Reception (age 4-5 years) and Year 6 (age 10-11 years) schoolchildren, 2007-2010.

\section{Key messages}

- At local authority level, there is a substantial association between obesity prevalence in Reception year and Year 6 and the IMD 2010.

- The associations between childhood overweight and obesity prevalence and IMD 2010 have not changed significantly from 2007 to 2010 .

- Primary healthcare professionals have a key role to play in delivering childhood obesity prevention messages to new parents, as part of a broad strategy to address childhood obesity.

Strengths and limitations of this study

- Participation bias is likely to have resulted in some underestimation of Year 6 obesity rates for 2007-2008 and 2008-2009.

- The IMD have some limitations but provide the best available means of comparing area deprivation in England.

- Changes were made to local authority boundaries in 2009; however, the sensitivity analysis demonstrated that this had no meaningful impact on the results.

- The strength of this study in comparison with previous analyses of the National Child Measurement Programme data is in using a more upto-date measure of deprivation to quantify the association between local authority deprivation and childhood overweight and obesity.

4-5 years) and Year 6 (age 10-11 years) attending non-specialist maintained state schools in England. The findings are used to inform planning and delivery of local services and document trends in childhood overweight and obesity. For the purposes of the NCMP, overweight is defined as a body mass index greater than or equal to the 85 th percentile but less than the 95th percentile; 
obesity is defined as a body mass index greater than or equal to the 95th percentile. NCMP data for 2006-2007 showed an obesity prevalence of $9.9 \%$ in Reception and $17.5 \%$ in Year 6. Prevalence of overweight was $13.0 \%$ in Reception and $14.2 \%$ in Year 6 . Obesity has been found to be consistently more prevalent among boys than among girls in both year groups. ${ }^{2-4}$ In 2008, the UK government announced its ambition to reduce the proportion of overweight and obese children to 2000 levels by 2020 as part of its overall goal of reversing the rising tide of unhealthy weight in the population. ${ }^{5}$

Some studies looking at a small geographical area have concluded that there is no association between deprivation and childhood obesity, ${ }^{6} 7$ whereas other small area studies have shown a positive association between obesity and both deprivation and affluence. ${ }^{8}{ }^{9}$ Analysis of the NCMP data across England since 2006-2007 shows a clear association between deprivation and obesity prevalence in both Reception and Year 6. No meaningful association was shown between deprivation and overweight. $^{2-4}$ Detailed interactive maps showing the geographical association between childhood obesity prevalence and deprivation are available online at the National Obesity Observatory website (http://www.noo. org.uk/visualisation/eatlas).

The NCMP's analysis was based on Indices of Multiple Deprivation (IMD) summary scores for each school area. In England, the IMD are used widely as a measure of deprivation across the country and as a tool to determine an area's eligibility for specific government funding streams. The NCMP analysis up to 2009-2010 used IMD 2007 scores, which are based on data from 2004 to 2005. The IMD 2010, released in March 2011, are based on data from 2007 to $2008,{ }^{10}$ providing a more up-to-date picture of deprivation over the period in which the NCMP has been under way. This allows a more accurate analysis of the contemporary association between deprivation and childhood overweight/obesity to be undertaken. Overall, the IMD 2010 shows broadly similar results to the IMD 2007, with $66 \%$ of areas in England in the same decile of the IMD 2010 as they were in the previous version. Similarly, there is little change at the top and bottom of the rankings (table 1). The broad agreement between the 2010 and 2007 IMDs masks some important shifts, however, including significantly greater deprivation in some highly deprived areas (relative to other local authorities); large increases in relative deprivation for coastal areas; and relative improvement in Inner London. ${ }^{11}$ Using local authority IMD 2010 scores, this study investigates the relationship between deprivation and childhood overweight/obesity from 2007 to 2010.

\section{METHODS}

\section{Data sources}

A data set was constructed from NCMP data and local authority IMD 2010 scores. Local authorities were the smallest geographical unit for which all the required data were readily available. Reception and Year 6 rates of obesity and overweight were obtained from the Eastern Public Health Observatory website (http://www.erpho. org.uk) for 2007-2008, 2008-2009 and 2009-2010 for all local authorities in England. Data for 2006-2007, the first year of NCMP results, were only available for upper tier local authorities and therefore were not included in the data set. Formal ethical approval for the study was

\begin{tabular}{|c|c|c|}
\hline & IMD 2007 & IMD 2010 \\
\hline \multirow[t]{10}{*}{ Ten most deprived local authorities (IMD score) } & Liverpool (46.97) & Liverpool (43.45) \\
\hline & Hackney (46.10) & Hackney (42.89) \\
\hline & Tower Hamlets (44.64) & Newham (41.84) \\
\hline & Manchester (44.50) & Manchester (41.13) \\
\hline & Knowsley (43.20) & Knowsley (41.01) \\
\hline & Newham (42.95) & Blackpool (40.39) \\
\hline & Islington (38.96) & Tower Hamlets (39.59) \\
\hline & Middlesbrough (38.94) & Middlesbrough (37.62) \\
\hline & Birmingham (38.67) & Birmingham (37.54) \\
\hline & Kingston upon Hull (38.31) & Kingston upon Hull (37.53) \\
\hline \multirow[t]{10}{*}{ Ten least deprived local authorities (IMD score) } & Chiltern (7.02) & St Albans (7.75) \\
\hline & Uttlesford (6.94) & Rushcliffe (7.61) \\
\hline & Mid Sussex (6.94) & Harborough (7.57) \\
\hline & Waverley (6.86) & Elmbridge (7.24) \\
\hline & West Oxfordshire (6.67) & Waverley (7.14) \\
\hline & South Cambridgeshire (6.55) & South Cambridgeshire (7.11) \\
\hline & South Northamptonshire (6.46) & South Northamptonshire (7.03) \\
\hline & Surrey Heath (5.75) & Surrey Heath (6.89) \\
\hline & Wokingham (5.36) & Wokingham (5.45) \\
\hline & Hart (4.13) & Hart (4.47) \\
\hline
\end{tabular}


not required as the data set comprised entirely of routine publicly available data.

IMD 2010 local authority deprivation scores were obtained from the Office for National Statistics website (http://www.neighbourhood.statistics.gov.uk). The indices are based on national routine data, including Census data, and cover a broad range of economic, social and housing issues, with each index composed of a number of indicators for a different aspect of deprivation. The IMD 2010 covered seven distinct domains: Income Deprivation, Employment Deprivation, Health Deprivation and Disability, Education Skills and Training Deprivation, Barriers to Housing and Services, Living Environment Deprivation and Crime. IMD summary scores combine these indices to provide a single deprivation score for each area.

Changes were made to local authority boundaries in 2009, which meant that some local authorities were abolished and some new ones created. Three hundred and fifteen local authorities $(89 \%)$ were included in the analysis of 2007-2008 data, and 323 local authorities (99\%) were included in the analysis of 2008-2009 and 2009-2010 data. There were 354 local authority districts in England prior to the 2009 boundary changes and 326 following the changes. The IMD 2010 applies to post-boundary change local authorities and therefore those which did not exist after 2009 were excluded from the analysis. NCMP data for City of London and Hackney had been combined to avoid disclosure of small numbers. Similarly, the data for the Isles of Scilly had been combined with the pre-2009 local authority of Penwith. This prevented meaningful analysis with IMD scores and therefore City of London, Hackney and the Isles of Scilly were excluded from the data set.

\section{Statistical analysis}

The data were analysed using StatsDirect statistical software. Standard parametric correlation analysis (Pearson's r) was carried out to measure the strength of the linear relationship between the IMD 2010 and the prevalence (by percentage) of overweight in Reception and Year 6 for each year of NCMP data. Changes in these correlations between 2007-2008 and 2009-2010 were tested for statistical significance using the Fisher r-to-z transformation. After first plotting the variables to check for a linear relationship, ordinary least squares linear regression modelling was then used to quantify the association between each set of overweight prevalence data (dependent variable) and the IMD 2010 (independent variable). The same method was used to measure the association between the prevalence of obesity and the IMD. Finally, a sensitivity analysis was conducted to test the impact of the changes in local authority boundaries on the results. This was done by repeating the correlation analysis and regression modelling using only the 315 local authorities included in the analysis of the 2007-2008 data (see appendix 1).

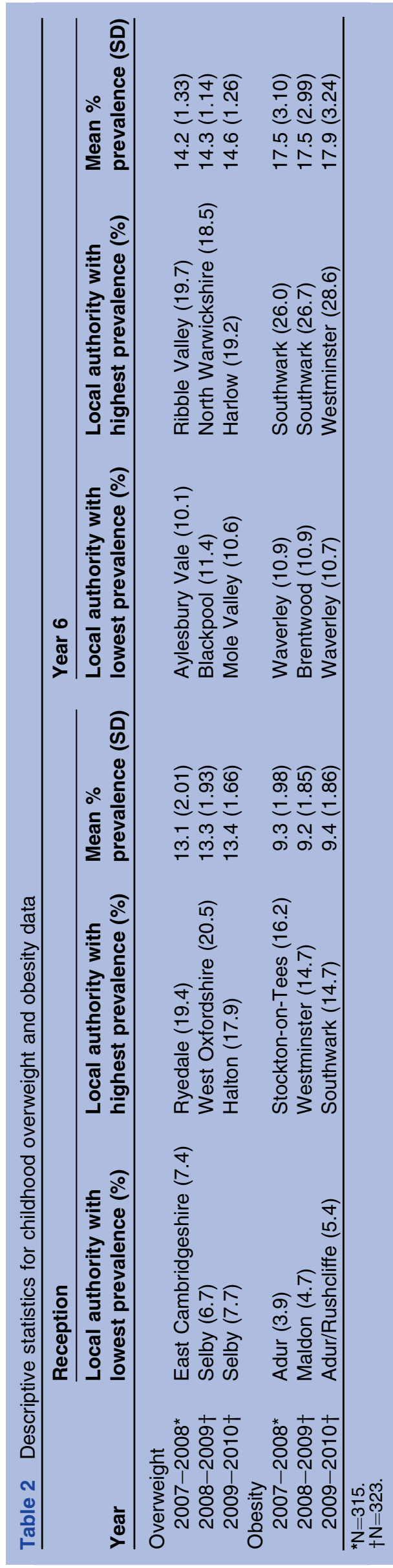


Table 3 Correlations and linear regression models for the relationships between Reception and Year 6 overweight prevalence, 2007-2010, and local authority IMD 2010 scores

\begin{tabular}{|c|c|c|c|c|c|c|c|c|}
\hline & \multicolumn{4}{|c|}{ Reception } & \multicolumn{4}{|c|}{ Year 6} \\
\hline & $r$ & $\mathbf{R}^{2}$ & $\beta$ & p Value & $r$ & $\mathbf{R}^{2}$ & $\beta$ & p Value \\
\hline $2007-2008^{*}$ & 0.111 & 0.012 & 0.027 & 0.049 & 0.207 & 0.043 & 0.033 & $<0.001$ \\
\hline 2008-2009† & 0.114 & 0.013 & 0.027 & 0.039 & 0.152 & 0.023 & 0.021 & 0.006 \\
\hline 2009-2010† & 0.095 & 0.009 & 0.019 & 0.092 & 0.184 & 0.034 & 0.028 & 0.001 \\
\hline
\end{tabular}

\section{RESULTS}

\section{Overweight and deprivation}

The prevalence of overweight in Reception in 2007-2008 ranged from $7.4 \%$ to $19.4 \%$, with a mean of $13.1 \%$. Prevalence in Reception in 2009-2010 ranged from $7.7 \%$ to $17.9 \%$, with a mean of $13.4 \%$. The prevalence of overweight in Year 6 in 2007-2008 ranged from $10.1 \%$ to $19.1 \%$, with a mean of $14.2 \%$. Prevalence in Year 6 in 2009-2010 ranged from $10.6 \%$ to $19.2 \%$, with a mean of $14.6 \%$ (table 2 ).

The prevalence of overweight was not statistically significantly correlated with local authority IMD 2010 scores in Reception for 2009-2010 ( $\mathrm{r}=0.095, \mathrm{p}=0.092)$, and only weakly associated in the preceding 2 years. Year 6 overweight prevalence was weakly associated with IMD scores in 2009-2010 $(\mathrm{r}=0.184, \mathrm{p}=0.001)$. Over the 3year period, there was no statistically significant change in correlation between overweight and IMD in either Reception $(\mathrm{z}=0.2, \mathrm{p}=0.842)$ or Year $6(\mathrm{z}=0.3, \mathrm{p}=0.764)$ (table 3).

\section{Obesity and deprivation}

The prevalence of obesity in Reception in 2007-2008 ranged from $3.9 \%$ to $16.2 \%$, with a mean of $9.3 \%$. Prevalence in Reception in 2009-2010 ranged from $5.4 \%$ to $14.7 \%$, with a mean of $9.4 \%$. The prevalence of obesity in Year 6 in 2007-2008 ranged from 10.9\% to $26.0 \%$, with a mean of $17.5 \%$. Prevalence in Year 6 in $2009-2010$ ranged from $10.7 \%$ to $28.6 \%$, with a mean of $17.9 \%$ (table 2).

In 2009-2010, local authority IMD 2010 scores were strongly correlated with obesity rates in Reception $(\mathrm{r}=0.625, \mathrm{p}=<0.001)$ and Year $6(\mathrm{r}=0.733, \mathrm{p}=<0.001)$. The association was statistically significant in both Reception and Year 6 for all 3 years of data (table 4 ). The
$\mathrm{R}^{2}$ figure shows that IMD accounted for $39.1 \%$ of the variation in obesity prevalence in Reception and $53.8 \%$ in Year 6 for 2009-2010. The change in correlation between obesity and IMD over the 3-year period was not statistically significant in either Reception $(\mathrm{z}=-1.64$, $\mathrm{p}=0.101)$ or Year $6(\mathrm{z}=0.19, \mathrm{p}=0.849)$.

\section{DISCUSSION}

There are clear inequalities in childhood obesity rates in England. The association between deprivation and childhood obesity prevalence was substantial. In the case of Reception obesity, this inequality increased notably from 2007 to 2010. There was no meaningful association between deprivation and overweight at Reception and Year 6 over the same period.

The data used in the study present some limitations. The NCMP has not achieved $100 \%$ participation, and participation bias is likely to have resulted in some underestimation of Year 6 obesity rates for 2007-2008 and 2008-2009. This was due to obese children being more likely to opt out of being measured than other children. ${ }^{4}$ In 2009-2010, the overall participation rate for the NCMP across Reception and Year 6 combined was $93 \%$, with a small number of areas achieving $<90 \%$ participation. This compares with a $90 \%$ overall participation rate in 2008-2009 and 88\% in 2007-2008. More detail on data quality and validation issues can be found in the NCMP's own annual reports and other supporting documents. $^{2-4} 12 \quad 13$ Another limitation is that local authorities are not comparable geographical units, with some considerable variation in scale and size of population. Also, the changes in local authority boundaries in 2009 mean that the data subset for 2007-2008 is not completely comparable with that of subsequent years. However, the sensitivity analysis demonstrated that these

Table 4 Correlations and linear regression models for the relationships between Reception and Year 6 obesity prevalence, 2007-2010, and local authority IMD 2010 scores

\begin{tabular}{|c|c|c|c|c|c|c|c|c|}
\hline & \multicolumn{4}{|c|}{ Reception } & \multicolumn{4}{|c|}{ Year 6} \\
\hline & $\mathbf{r}$ & $\mathbf{R}^{2}$ & $\beta$ & p Value & $r$ & $\mathbf{R}^{2}$ & $\beta$ & p Value \\
\hline $2007-2008^{*}$ & 0.539 & 0.290 & 0.127 & $<0.001$ & 0.740 & 0.547 & 0.273 & $<0.001$ \\
\hline $2008-2009+$ & 0.612 & 0.375 & 0.136 & $<0.001$ & 0.737 & 0.543 & 0.265 & $<0.001$ \\
\hline 2009-2010† & 0.625 & 0.391 & 0.140 & $<0.001$ & 0.733 & 0.538 & 0.285 & $<0.001$ \\
\hline
\end{tabular}


changes had no meaningful impact on the outcome of the analysis (see appendix 1). The IMD also have some limitations. ${ }^{14}$ They are not a direct measure of deprivation, and therefore, an area with an IMD score of 50, for example, cannot be said to be twice as deprived as one with a score of 25. Changes in an area's IMD score over time are based on how its level of deprivation has changed relative to other areas. This limits meaningful comparison of scores over time in a single area but is less of an issue when analysing changes in inequalities across all areas, as with this study. Also, it has been suggested that the IMD are biased against rural areas, where deprivation is more heterogeneous. Despite these limitations, the IMD provide the best available means of comparing area deprivation in England.

While this study shows clear overall patterns of association between deprivation and childhood obesity in England, it may mask variations in that association between and within individual local authorities. Also, as with any ecological analysis, causation cannot be inferred from the results. Unlike studies investigating the attitudes and circumstances of individuals, ${ }^{15-17}$ this study cannot offer insight into the causes of childhood obesity or what lies behind the association between childhood obesity and deprivation. However, the strength of this study in comparison with previous analyses of the NCMP data is in using a more up-to-date measure of deprivation to quantify the association between local authority deprivation and childhood overweight and obesity.

The association between deprivation and childhood obesity in England reflects that in the USA and other developed countries. ${ }^{18}$ The absence of a meaningful association between deprivation and childhood overweight is likely to be the result of various social and cultural changes over recent decades, which have simultaneously increased children's energy intake and decreased their energy expenditure across the socioeconomic spectrum. ${ }^{19}$ Efforts to prevent unhealthy weight in children are therefore needed in all local authorities, irrespective of their level of deprivation, although children in more deprived areas are at greater risk of going on to become obese. As deprivation is more strongly linked to obesity risk in Year 6 than in Reception, preventive intervention may be more effective at an earlier stage, before factors linked to deprivation have their full impact. Differences in parents' beliefs about appropriate infant size, growth and feeding behaviour have been found to be early predictors of childhood obesity, ${ }^{17}$ suggesting that routine contact with health services by pregnant women and new parents may present a valuable opportunity to deliver obesity prevention education. Any intervention, however, will need to be part of a broad approach to tackling childhood obesity, addressing factors that contribute to the obesogenic environment. ${ }^{20}$ Such a strategy would need to tackle issues of food supply and the marketing of food and drinks to children, create environments conducive to physical activity, communicate health messages more effectively and improve access to community-wide programmes and health services. ${ }^{21}$ No single intervention is likely to provide the solution in isolation, as childhood obesity results from an interplay of various causal factors, ${ }^{22}$ the nature of which remains to be fully understood. For example, popular perceptions that neighbourhood variations in access to fast food outlets are an important determinant of obesity in young people have been shown to be overly simplistic. ${ }^{23}$ Failure to improve the lifestyles of future generations of children, however, particularly in more deprived areas, will inevitably lead to greater morbidity and further burdening of health services in years to come.

Contributors DC: conception and design; acquisition of data; analysis and interpretation of data; drafting the article; final approval of the version to be published. SC: conception and design, critical revision of article; final approval of the version to be published.

Funding This research received no specific grant from any funding agency in the public, commercial or not-for-profit sectors.

Competing interests None.

Provenance and peer review Not commissioned; externally peer reviewed.

Data sharing statement No additional data available.

\section{REFERENCES}

1. Kimm SY, Obarzanek E. Childhood obesity: a new pandemic of the new millennium. Pediatrics 2002;110:1003-7.

2. The NHS Information Centre. National Child Measurement Programme 2007/08 School Year Headline Results. London: DH, 2008.

3. The NHS Information Centre. National Child Measurement Programme: England, 2008/09 School Year. London: DH, 2009.

4. The NHS Information Centre. National Child Measurement Programme: England, 2009/10 School Year. London: DH, 2010.

5. DH. Healthy Weight, Healthy Lives: A Cross-Government Strategy for England. London: DH, 2008.

6. Dummer TJ, Gibbon MA, Hackett AF, et al. Is overweight and obesity in 9-10-year-old children in Liverpool related to deprivation and/or electoral ward when based on school attended? Public Health Nutr 2005;8:636-41.

7. BBC News. Obesity Not Linked to Deprivation. 2008. http://news.bbc. co.uk/1/hi/england/norfolk/7225262.stm

8. Procter KL, Clarke GP, Ransley JK, et al. Micro-level analysis of childhood obesity, diet, physical activity, residential socio-economic and social capital variables: where are the obesogenic environments in Leeds? Area 2008;40:323-40.

9. Edwards KL, Cade JE, Ransley JK, et al. A cross-sectional study examining the pattern of childhood obesity in Leeds: affluence is not protective. Arch Dis Child 2010;95:94-9.

10. Department for Communities and Local Government. Indices of deprivation 2010. 2011. http://www.communities.gov.uk/ communities/research/indicesdeprivation/deprivation10/

11. Oxford Consultants for Social Inclusion. Headline Results From the Indices of Deprivation 2010. 2011. http://www.ocsi.co.uk/news/2011/ 03/24/headline-results-from-the-indices-of-deprivation-2010/

12. The NHS Inf Centre Data quality Statement. Natl Child Meas Programme England 2009/1 School Year. 2010. http://www.ic.nhs.uk webfiles/publications/003_Health_Lifestyles/ncmp/NCMP_200910_data_quality_statement.pdf

13. The NHS Information Centre. National Child Measurement Programme: NHS Information Centre Validation Process for NCMP Data. London: DH, 2009.

14. Oxford Consultants for Social Inclusion. Why the Indices of Deprivation are Still Important in the Open Data Era. 2011. http:// www.ocsi.co.uk/news/2011/03/24/why-the-imd-is-still-important-inthe-open-data-age

15. Jain A, Sherman SN, Chamberlin LA, et al. Why don't low-income mothers worry about their preschoolers being overweight? Pediatrics 2001;107:1138-46.

16. Saxton J, Hill C, Chadwick $P$, et al. Weight status and perceived body size in children. Arch Dis Child 2009;94:944-9.

17. Redsell SA, Atkinson P, Nathan D, et al. Parents' beliefs about appropriate infant size, growth and feeding behaviour: implications 
for the prevention of childhood obesity. BMC Public Health 2010;10:711.

18. Shrewsbury V, Wardle J. Socioeconomic status and adiposity in childhood: a systematic review of cross-sectional studies 1990-2005. Obesity (Silver Spring) 2008;16:275-84.

19. Anderson PM, Butcher KF. Childhood obesity: trends and potential causes. Future Child 2006;16:19-45.

20. Rudolph MC. The obese child. Arch Dis Child Educ Pract Ed 2004;89: ep57-62.

21. Swinburn BA, Caterson I, Seidell JC, et al. Diet, nutrition and the prevention of excess weight gain and obesity. Public Health Nutr 2004; 7:123-46.

22. Lieb DC, Snow RE, DeBoer MD. Socioeconomic factors in the development of childhood obesity and diabetes. Clin Sports Med 2009;28:349-78.

23. Richardson AS, Boone-Heinonen J, Popkin BM, et al. Neighborhood fast food restaurants and fast food consumption: a national study. BMC Public Health 2011;11:543.

\section{APPENDIX 1}

To test the impact of the 2009 changes in local authority boundaries, a sensitivity analysis was conducted. The regression modelling was repeated using only data for local authorities with boundaries that remained unchanged from 2007 to 2010 , excluding the local authorities removed from the data set because of combined rates $(\mathrm{N}=315)$.

The results of the sensitivity analysis show that there remains no meaningful association between childhood overweight and IMD 2010 from 2007 to 2010 after removing from the analysis those local authorities, which existed only before or after 2009 (table Al). The substantial association between childhood obesity prevalence and IMD 2010 over the same period also remains (table All). In both sets of analysis, the correlation coefficients and regression output vary only slightly from those reported in the main body of the study.

Table Al Correlations and linear regression models for the relationships between Reception and Year 6 overweight prevalence, 2007-2010, and local authority IMD 2010 scores for local authorities that remained unchanged during that period $(\mathrm{N}=315)$

\begin{tabular}{|c|c|c|c|c|c|c|c|c|}
\hline & \multicolumn{4}{|c|}{ Reception } & \multicolumn{4}{|c|}{ Year 6} \\
\hline & $r$ & $\mathbf{R}^{2}$ & $\beta$ & $p$ Value & $r$ & $\mathbf{R}^{2}$ & $\beta$ & $p$ Value \\
\hline 2007-2008 & 0.111 & 0.012 & 0.027 & 0.049 & 0.207 & 0.043 & 0.033 & $<0.001$ \\
\hline 2008-2009 & 0.115 & 0.013 & 0.027 & 0.041 & 0.150 & 0.022 & 0.020 & 0.008 \\
\hline 2009-2010 & 0.097 & 0.009 & 0.019 & 0.085 & 0.184 & 0.034 & 0.028 & 0.001 \\
\hline
\end{tabular}

Table All Correlations and linear regression models for the relationships between Reception and Year 6 obesity prevalence, 2007-2010, and local authority IMD 2010 scores for local authorities that remained unchanged during that period ( $N=315)$

\begin{tabular}{|c|c|c|c|c|c|c|c|c|}
\hline & \multicolumn{4}{|c|}{ Reception } & \multicolumn{4}{|c|}{ Year 6} \\
\hline & $r$ & $\mathbf{R}^{2}$ & $\beta$ & p Value & $r$ & $\mathbf{R}^{2}$ & $\beta$ & p Value \\
\hline $2007-2008$ & 0.539 & 0.290 & 0.127 & $<0.001$ & 0.740 & 0.547 & 0.273 & $<0.001$ \\
\hline 2008-2009 & 0.611 & 0.373 & 0.136 & $<0.001$ & 0.737 & 0.543 & 0.265 & $<0.001$ \\
\hline 2009-2010 & 0.626 & 0.392 & 0.140 & $<0.001$ & 0.733 & 0.537 & 0.285 & $<0.001$ \\
\hline
\end{tabular}

